\title{
Formation of ohmic contacts to $n(p)$-gan and measurement of their contact resistivity
}

\author{
M.S. Boltovets ${ }^{1}$, V.M. Ivanov ${ }^{1}$, R.V. Konakova ${ }^{2}$, Ya.Ya. Kudryk ${ }^{2}$, V.V. Milenin ${ }^{2}$, V.V. Shynkarenko ${ }^{2}$, \\ V.M. Sheremet ${ }^{2}$, Yu.N. Sveshnikov ${ }^{3}$, B.S. Yavich ${ }^{4}$ \\ ${ }^{1}$ State Enterprise Research Institute “Orion”, 8a Eugene Pottier St., Kyiv 03057, Ukraine, \\ ${ }^{2} V$. Lashkaryov Institute of Semiconductor Physics, NAS Ukraine \\ 41 Prospect Nauky, Kyiv 03028, Ukraine \\ Tel.: (380-44) 525-61-82; Fax: (380-44) 525-83-42; e-mail: konakova@isp.kiev.ua, \\ ${ }^{3}$ Close Corporation "Elma-Malakhit”, Zelenograd, Russia; e-mail: info@emal.zelcom.ru \\ ${ }^{4}$ Close Corporation "Svetlana-Optoelektronika”, Sankt-Peterburg, Russia
}

\begin{abstract}
We propose multilayer ohmic contacts to $n$ - and $p$-GaN layers, with titanium boride as diffusion barrier. It is shown that the optimal method of contact resistivity measurement is the transmission line method (TLM) with circular contact geometry. The $\mathrm{Ti}-\mathrm{Al}-\mathrm{TiB}_{x}-\mathrm{Au}$ contact metallization to $n-\mathrm{GaN}$ retains its layer structure after thermal annealing at temperatures up to $900{ }^{\circ} \mathrm{C}$. The contact resistivity $\rho_{\mathrm{c}}$ is $(6.69 \pm 1.67) \times 10^{-5}$ $\Omega \cdot \mathrm{cm}^{2}$. For the $\mathrm{Au}-\mathrm{TiB}_{x}-\mathrm{Ni}-p-\mathrm{GaN}$ contact structure, the contact resistivity is $(1 \pm 0.15) \times 10^{-3} \Omega \cdot \mathrm{cm}^{2}$.
\end{abstract}

Keywords: ohmic contact, gallium nitride, contact resistivity, transmission line method.

Manuscript received 22.07.10; accepted for publication 02.12.10; published online 30.12.10.

\section{Introduction}

In recent years, the lighting engineering dealing with production of light-emitting diodes (LEDs) for various purposes has been developing intensely. Having higher light efficiency and longer service life, LEDs rather actively displace other illuminators such as incandescent and luminescent lamps [1,2]. The process has become more evident after appearance of highly efficient LEDs based on the III group nitrides that made it possible to develop blue LEDs and, closing the RGB range, obtain white light using concurrently red, green and blue LEDs. Such three-color cells are of importance for developing of LED monitors.

It is known that one cannot realize such properties of gallium nitride (that is the most advanced material of the III group nitrides) as high value of avalanche breakdown field and thermal stability without highly reliable ohmic contacts. The reason is that application of LEDs for illumination requires increase of power of the present-day diodes. In this case, LED heating in both the base region and contacts will lead to device degradation. Therefore, search for contact metallization systems to gallium nitride LEDS that would be high-tech, thermally stable and compatible with technological processes for microwave devices makes a topical problem.

Another (no less important) problem in development of investigations of contact metallization to $\mathrm{GaN}$ is making of low-resistance thermally stable contacts to $p$ $\mathrm{GaN}$. The existing experimental data on the resistivity $\rho_{\mathrm{c}}$ for contacts to $p$-GaN indicate wide spread of $\rho_{\mathrm{c}}$ values depending on the level of doping with acceptor impurity and crystallographic orientation of $\mathrm{GaN}$ surface as well as on the work function $\varphi_{\mathrm{m}}$ of the material of contactforming layer. The latter can be formed with multicomponent compounds with high $\varphi_{\mathrm{m}}$ value [3-8].

Reduction of resistivity $\rho_{\mathrm{c}}$ of contact to $p-\mathrm{GaN}$ can be achieved (along with choosing the appropriate value of $\left.\varphi_{\mathrm{m}}\right)$ by doping the near-surface layer with an acceptor impurity that provides tunnel current transport in the ohmic contact. The theoretical studies of $\rho_{\mathrm{c}}$ for contact to $p$-GaN showed [8] that, in the case of a tunnel contact and with allowance made for tunneling of light and heavy holes, $\rho_{\mathrm{c}}$ value depends on the crystallographic orientation of GaN. The calculated $\rho_{\mathrm{c}}$ value of about $2 \times 10^{-4} \Omega \cdot \mathrm{cm}^{2}$ corresponds to concentration of noncompensated acceptors $\sim 10^{19} \mathrm{~cm}^{-3}$ for GaN [0001] and $5 \times 10^{18} \mathrm{~cm}^{-3}$ for GaN [1010], respectively. 
At the same time, it turned out that, along with the well-known mechanisms of current transport in ohmic contacts to $n$-GaN grown on sapphire, metallic conductance is observed in such contacts over a wide temperature range. The reason is high density of structural defects in GaN. Increase of $\rho_{\mathrm{c}}$ as temperature grows (and contributes to device structure heating) is undesirable not only for LEDs but for other types of GaN-based electronic devices as well. Thus, formation of metal-GaN interface with preset parameters as well as making of buffer layers (diffusion barriers) between the upper metallization layer and contact-forming layer that impede mass transfer of contact components are topical from the viewpoint of production of highly reliable thermally stable ohmic contacts to $n(p)-\mathrm{GaN}$ epitaxial layers grown on foreign substrates.

Therefore, one should use multilayer contact metallizations (made of refractory metals and their compounds) serving as diffusion barriers. In this connection, borides and nitrides of refractory metals seem most promising [9-11]. Choice of procedures and estimation of $\rho_{\mathrm{c}}$ measurement errors are of great importance too. In this work, we studied efficiency of $\mathrm{TiB}_{x}$ as diffusion barrier in ohmic contacts to GaN using the transmission line method (TLM) to measure $\rho_{\mathrm{c}}$.

\section{Methods of contact resistance measurement}

Contact resistivity is one of the main parameters that characterizes both an ohmic contact and processes of heat release in it. The principal difficulty in measurement of contact resistance is its determination from the measured resistance $R$. The latter can be represented as a sum of resistances of the contacts $\left(R_{\mathrm{c}}\right)$, semiconductor $\left(R_{\mathrm{s}}\right)$, probes and lead-ins $\left(R_{\mathrm{p}}\right)$ and the resistance provoked by current spreading $\left(R_{\mathrm{T}}\right)$ [12]:

$$
R=R_{c}+R_{s}+R_{T}+R_{p} \text {. }
$$

It was shown in [13] that the biggest error in determination of contact resistivity is characteristic of the method with vertical geometry of test structure (the Cox-Strack method) [14-16]. In this method, the minimal relative error of $\rho_{\mathrm{c}}$ measurement (at $\rho_{\mathrm{c}} / \rho_{\mathrm{s}}=0.01$ $\mathrm{cm}$, where $\rho_{\mathrm{s}}$ is the semiconductor resistivity) is as high as $90 \%$ if one uses lithography with accuracy of $2.5 \mu \mathrm{m}$ [13]. Therefore, it is reasonable to apply the Cox-Strack method [14] only if one has to measure the parameters of contacts to bulk material and in the case $\rho_{\mathrm{c}} \geq \rho_{\mathrm{s}}$. The minimal value of error is ensured by the method of interface probing [17] and Kelvin method [16, 18, 19]. At $\rho_{\mathrm{c}} / \rho_{\mathrm{s}}=0.01 \mathrm{~cm}$, the relative error of $\rho_{\mathrm{c}}$ measurement is $25 \%$ and $15 \%$, respectively, if one uses lithography with accuracy of $2.5 \mu \mathrm{m}$ [13]. When using the probing method, the lithography should enable one to deposit sufficiently small external terminals, while application of the Kelvin method for measurement of low resistances requires contacts smaller than $1 \mu \mathrm{m} \times 1 \mu \mathrm{m}$ [19].
The most convenient and sufficiently accurate methods are those TLM versions [20-27] that make it possible to measure low contact resistances, and the lithography used meets the requirements to making test structures for measurements. TLM has many modifications that differ in geometry and $\rho_{\mathrm{c}}$ calculation technique. One should set off the versions of TLM with linear and circular contact geometry.

The necessary condition for resistance measurement by TLM with linear geometry of contact pads is absence of edge surface spreading of current. To this end, each group of contacts has to be separated from the rest part of semiconductor plate. This requires application of additional technological process. Contrary to this, use of structures with circular geometry of contact pads makes it possible to avoid edge spreading of current without additional treatment $[25,26]$.

In the TLM with circular geometry, the resistance between contact pads is determined with the following expression [25]:

$R=\frac{R_{S H}}{2 \pi} \ln \frac{r_{2}}{r_{1}}+\frac{R_{S H}}{2 \pi} \frac{1}{\alpha r_{1}} \frac{I_{0}\left(\alpha r_{1}\right)}{I_{1}\left(\alpha r_{1}\right)}$

Here $r_{1}\left(r_{2}\right)$ is the inner (outer) radius of the corresponding contact pad, $I_{0}\left(\alpha r_{1}\right)$ and $I_{1}\left(\alpha r_{1}\right)$ the modified Bessel functions of the zeroth and first order, respectively, $\quad \alpha=1 / L_{T}$ the damping coefficient, $L_{T}=\sqrt{\rho_{c} t / \rho_{s}}$ transfer length, $t$ thickness of the semiconductor epitaxial layer.

If $L_{T} \gg r_{1}$ and $\ln \left(r_{2} / r_{1}\right)=C$, then the approximation $I_{0}\left(\alpha r_{1}\right) / I_{1}\left(\alpha r_{1}\right) \rightarrow 2 / \alpha r_{1}$ is valid, and the resistance measured is determined as [25]:

$R=\frac{C R_{S H}}{2 \pi}+\frac{\rho_{c}}{\pi r_{1}^{2}}$.

Thus, by plotting the dependence $R=f\left(1 / \pi r_{1}^{2}\right)$, one can calculate $\rho_{c}$ from the slope of the straight line. If $L_{T} \leq r_{1}$, then the value obtained in the above way will give the upper estimate for contact resistivity [25].

One should note that, to determine contact resistivity accurately, the difference between the outer and inner radii of contact pad has to be minimal. In that case, the contribution from semiconductor resistance to the total resistance becomes smaller [21]. The relative error of contact resistivity measurement can be determined from the following expression [13]:

$$
\frac{\Delta \rho_{c}}{\rho_{c}}=2 \frac{\Delta l}{r}+\frac{\Delta R}{R}+\frac{\rho_{s}}{\rho_{c}} \frac{C r^{2}}{2 t}\left(\frac{\Delta R}{R}+\frac{\Delta t}{t}\right),
$$

where $\Delta t$ is inaccuracy of the grown epitaxial layer thickness, $\Delta l$ inaccuracy of lithography when depositing contacts. The results of calculation of the dependence $f(r)=\Delta \rho_{\mathrm{c}} / \rho_{\mathrm{c}}$ are shown in Fig. 1 . At best, if $\rho_{\mathrm{c}} / \rho_{\mathrm{s}}=0.01$ $\mathrm{cm}^{-1}$, the relative inaccuracy of $\rho_{\mathrm{c}}$ measurement is $28 \%$. 


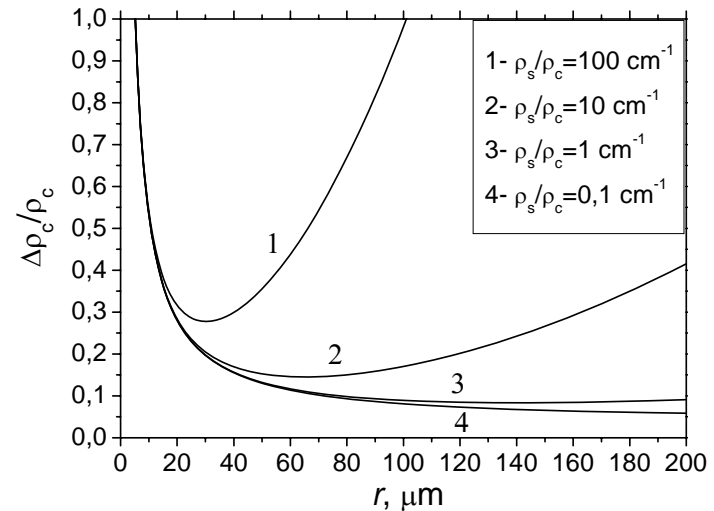

Fig. 1. Dependence of relative inaccuracy of contact resistivity measurement on contact radius when using TLM with circular contact geometry [13].

If one uses TLM with linear geometry of contact pads and $\rho_{\mathrm{c}} / \rho_{\mathrm{s}}=0.01 \mathrm{~cm}$ and $\rho_{\mathrm{s}}=10^{-4} \Omega \cdot \mathrm{cm}$, the relative inaccuracy of $\rho_{\mathrm{c}}$ measurement is $16 \%$ [13]. This value is below that obtained in the case of TLM with circular geometry. However, as $\rho_{\mathrm{s}}$ increases to $10^{-2} \Omega \cdot \mathrm{cm}$, the relative inaccuracy in the case of TLM with linear geometry grows to $50 \%$, contrary to the case of TLM with circular geometry in which the error does not depend on the value of semiconductor resistivity.

\section{Formation of contact systems}

To measure resistivity of ohmic contacts to $n$ - and $p$ $\mathrm{GaN}$, we chose TLM with circular geometry of contact pads. We made a test pattern with circular geometry of contacts (Fig. 2) and test TLM structures to measure $\rho_{\mathrm{c}}$.

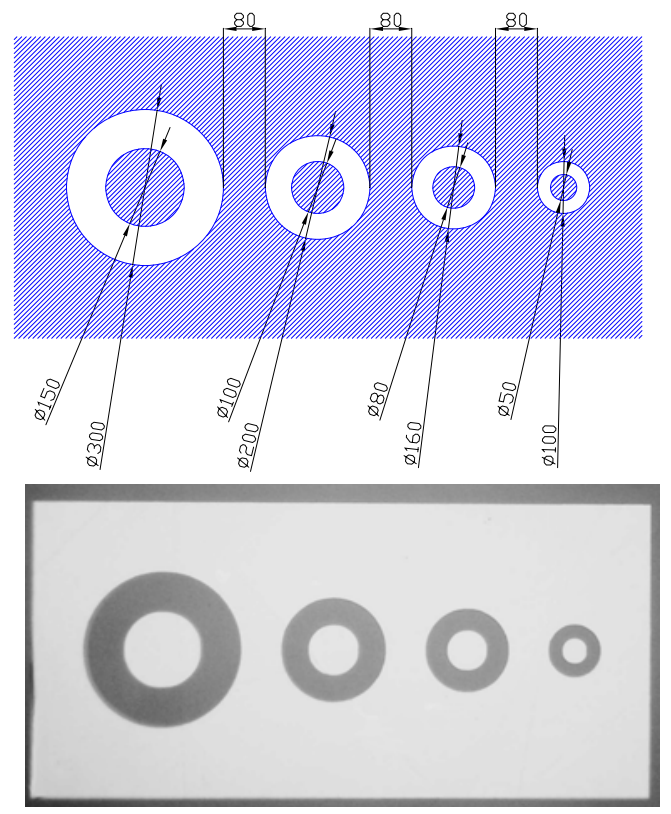

Fig. 2. Contact structure pattern for $\rho_{\mathrm{c}}$ measurement (a) and design of a contact structure formed on $\mathrm{GaN}$ to measure $\rho_{\mathrm{c}}$ (b). (The sizes are given in $\mu \mathrm{m}$.)
The GaN epitaxial structures were MOCVD-grown on the sapphire (0001) substrates $400 \mu \mathrm{m}$ thick. The LED structures were made at the Close Corporation "Svetlana-Optoelektronika", Sankt-Peterburg, Russia. A low-temperature nucleating layer, $n$-GaN layer $(3.5 \mu \mathrm{m})$, active area with five InGaN/GaN quantum wells, $p$ AlGaN current-limiting layer $(20 \mathrm{~nm})$ and $p$-GaN layer $(0.1 \mu \mathrm{m})$ with dopant concentration $>2 \times 10^{17} \mathrm{~cm}^{-3}$ were grown successively on the sapphire substrate. The $n^{+}-n$ $n^{+}-\mathrm{GaN}-\mathrm{Al}_{2} \mathrm{O}_{3}$ epitaxial structures were grown at the Close Corporation "Elma-Malakhit", Zelenograd, Russia. The layer parameters were as follows: $n^{+} \approx 10^{18}$ $\mathrm{cm}^{-3}, d_{n^{+}} \approx 0.8 \mu \mathrm{m} ; n \approx 10^{17} \mathrm{~cm}^{-3}, d_{n} \approx 3 \mu \mathrm{m}$; buffer layer: $n^{+} \approx 10^{18} \mathrm{~cm}^{-3}, d_{n^{+}} \approx 3 \mu \mathrm{m}$.

The dislocation density in structures of both types was over $10^{8} \mathrm{~cm}^{-2}$. The successive $\mathrm{Ti}-\mathrm{Al}-\mathrm{TiB}_{x}-\mathrm{Au}$ $\left(\mathrm{Ni}-\mathrm{TiB}_{x}-\mathrm{Au}\right)$ metallization layers to form ohmic contact to $n^{+}-\mathrm{GaN} \quad(p-\mathrm{GaN})$ were deposited with magnetron sputtering in the argon atmosphere onto the gallium nitride surface subjected to photon cleaning. After sputtering the Ti-Al (Ni) layer to $n-\mathrm{GaN}$ ( $p-\mathrm{GaN})$, the samples were subjected to rapid thermal annealing (RTA) at $T=900{ }^{\circ} \mathrm{C}$ in the nitrogen atmosphere for $30 \mathrm{~s}$. Then the $\mathrm{TiB}_{x}$ and $\mathrm{Au}$ layers were deposited. As a result, the ohmic contacts $\mathrm{Au}-\mathrm{TiB}_{x}-\mathrm{Al}-\mathrm{Ti}-n-\mathrm{GaN}$ and $\mathrm{Au}-\mathrm{TiB}_{x}-\mathrm{Ni}-p-\mathrm{GaN}$ were formed.

The contact resistivity was studied for the $\mathrm{Au}-\mathrm{TiB}_{x}-\mathrm{Al}-\mathrm{Ti}-n-\mathrm{GaN}$ contact structures before and after RTA at $T=700^{\circ} \mathrm{C}, 870^{\circ} \mathrm{C}$ and $900^{\circ} \mathrm{C}$ for $60 \mathrm{~s}$ and $\mathrm{Au}-\mathrm{TiB}_{x}-\mathrm{Ni}-p-\mathrm{GaN}$ contact structures before and after RTA at $700^{\circ} \mathrm{C}$ for $60 \mathrm{~s}$. We used the developed plant for measurement of parameters of ohmic contacts to semiconductors (Fig. 3), as well as Auger electron spectroscopy with ion etching by an argon beam (energy of $1 \mathrm{keV}$ ) to determine concentration depth profiles of metallization components.

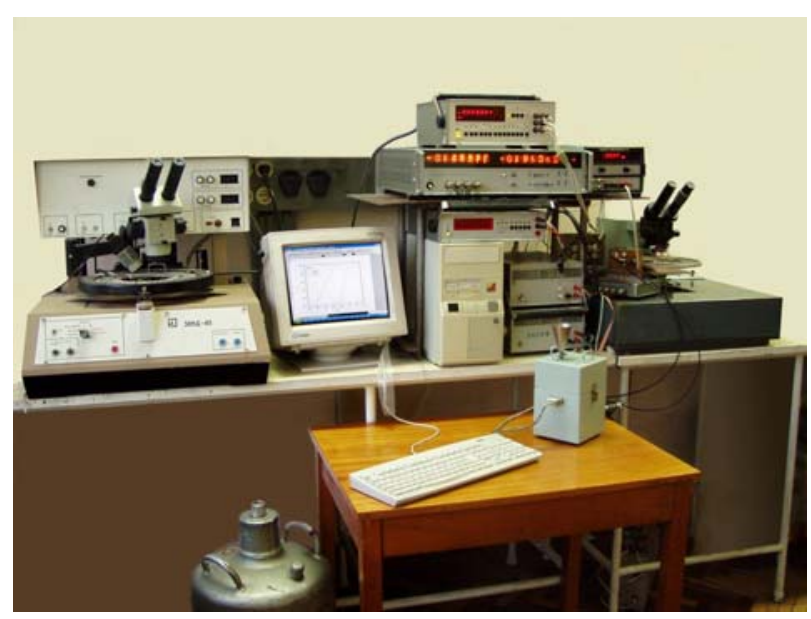

Fig. 3. The plant for measurement of parameters of ohmic contact to semiconductor. 


\section{Structure of contacts before and after RTA}

It was shown in [29] that the contacts with $\mathrm{TiB}_{\mathrm{x}}$ antidiffusion layer (barrier) demonstrate better thermal stability than those with more widespread metallization with $\mathrm{Ti}$ and $\mathrm{Al}$ as diffusion barrier. As in [29], our analysis of the concentration depth profiles for components of the $\mathrm{Ti}-\mathrm{Al}-\mathrm{TiB}_{x}-\mathrm{Au}$ contacts to $n$-GaN taken before and after RTA at $T=700{ }^{\circ} \mathrm{C}$ in the nitrogen atmosphere for $60 \mathrm{~s}$ showed that no interactions between phases in the contact metallization. Some changes in the layer structure of such contact were observed after RTA at a temperature of $900{ }^{\circ} \mathrm{C}$ only. One should also note considerable oxygen concentration in the $\mathrm{TiB}_{x}$ layer. Therefore, one may assume presence of titanium oxyboride instead of single-phase of $\mathrm{TiB}_{2}$ in it. This may be the reason for contact metallization structural failure in the course of RTA at a temperature of $900{ }^{\circ} \mathrm{C}$.

It was noted in a number of works [3-5, 30-32] that formation of ohmic contact to $n$-GaN with contactforming layers of $\mathrm{Al}-\mathrm{Ti}$ occurs owing to appearance at RTA of TiN composition whose work function is $3.87 \mathrm{eV}$, i.e., below that of pure $\mathrm{Ti}(3.95 \mathrm{eV})$. In this case, nitrogen vacancies are produced in the GaN near-surface layer because of $\mathrm{N}$ atoms coming to the titanium film. These nitrogen vacancies are shallow donors in $n-G a N$. They produce a thin $n^{+}$-layer in the near-contact region, thus ensuring, along with TiN, barrier lowering and decrease of $\rho_{\mathrm{c}}$. In our case, however, the x-ray diffraction pattern had no indications at presence of TiN phase. This may be owing to either small amount of titanium nitride or quasiamorphous nature of the compound obtained.

Formation of ohmic contact to $p$-GaN at RTA of nickel film occurs due to production of intermetallic compounds of nickel and gallium, with appearance in the GaN near-contact region of gallium vacancies serving as acceptors $[6,7]$.

\section{Electrophysical properties of ohmic contacts}

\section{1. $A u-T i B_{x}-A l-T i-n^{+}-n-n^{+}-G a N$ ohmic contacts.}

The $I-V$ curves of $\mathrm{Ti}-\mathrm{Al}-\mathrm{TiB}_{x}-\mathrm{Au}$ contacts to the $n^{+}-n-$ $n^{+}-\mathrm{GaN}$ structure taken in the $90-380 \mathrm{~K}$ temperature range turned out to be linear over the whole this range. The contact resistivity at room temperature was $(6.69 \pm 1.67) \cdot 10^{-5} \Omega \cdot \mathrm{cm}^{2}$ (Fig. 4). The semiconductor resistivity estimated from the dependence $R\left(1 / \pi r^{2}\right)$ was $\sim 10^{-2} \Omega \cdot \mathrm{cm}$.

The current through the $\mathrm{Au}-\mathrm{TiB}_{x}-\mathrm{Al}-\mathrm{Ti}-n^{+}-n-n^{+}-$ $\mathrm{GaN}$ contact structure is determined by the semiconductor resistance because structure conductance increases as temperature grows up to $150 \mathrm{~K}$. Further temperature increase led to decrease of conductance. This fact correlates with the temperature dependence of electron mobility in GaN considered in [33].

The contact resistivity measurements in the 225-380 K temperature range showed that there are two regions of $\rho_{\mathrm{c}}$ variation. In the $225-335 \mathrm{~K}$ temperature

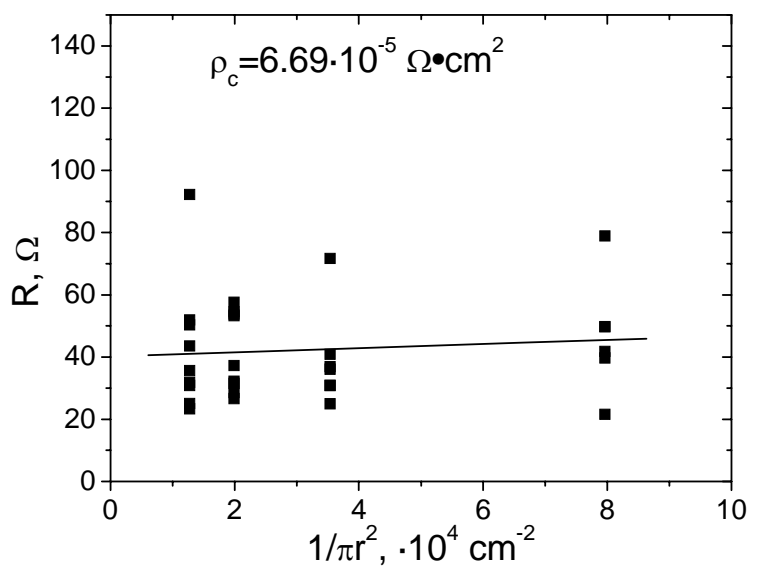

Fig. 4. The total resistance of $\mathrm{Au}-\mathrm{TiB}_{x}-\mathrm{Al}-\mathrm{Ti}-n-\mathrm{GaN}$ contacts as function of $\frac{1}{\pi r^{2}}$.

range, $\rho_{\mathrm{c}}$ practically does not depend on temperature. This is characteristic of the tunnel mechanism of current transport in the contact. In the 335-380 K temperature range, $\rho_{\mathrm{c}}$ decreases exponentially with temperature and is linear in the coordinates $\ln \left(\rho_{\mathrm{c}} T\right)=f(1 / T)$. This is characteristic of the thermionic mechanism of current transport. The potential barrier height $\varphi_{\mathrm{B}}$ determined from the dependence $\ln \left(\rho_{c} T\right)=f(q / k T)$ in the $335-380 \mathrm{~K}$ temperature range was $0.16 \mathrm{eV}$.

In the $225-335 \mathrm{~K}$ temperature range, the tunnel mechanism via dislocations of current transport is characteristic of the contact structure. The dislocation density in some samples was $\sim 10^{8} \mathrm{~cm}^{-2}$. The current transport mechanism via dislocations was observed in [34] for gallium nitride Schottky barrier diodes. In that case, the dislocation density in GaN was $\sim 10^{8}-10^{10} \mathrm{~cm}^{-2}$. Such mechanism was advanced earlier to describe the temperature dependence of saturation current in the GaP-based surface-barrier diodes [35].

For the best gallium nitride epitaxial structures with $\mathrm{Au}-\mathrm{TiB}_{x}-\mathrm{Al}-\mathrm{Ti}-n-\mathrm{GaN}$ ohmic contacts, the contact resistivity was $\sim 10^{-6} \Omega \cdot \mathrm{cm}^{2}$. After repeated RTA of the $\mathrm{Au}-\mathrm{TiB}_{x}-\mathrm{Al}-\mathrm{Ti}-n-\mathrm{GaN}$ contacts at $T=700^{\circ} \mathrm{C}$ and $T=$ $870^{\circ} \mathrm{C}$, the current transport mechanism and ohmic contact parameters did not change considerably. This indicates their thermal resistance.

\subsection{Au-TiB $B_{x}-N i-p-G a N$ ohmic contacts.}

The $I-V$ curves of the $\mathrm{Au}-\mathrm{TiB}_{x}-\mathrm{Ni}-p-\mathrm{GaN}$ contact structure subjected to RTA at $T=700{ }^{\circ} \mathrm{C}$ for $60 \mathrm{~s}$ were linear. The contact resistivity was $(1 \pm 0.15) \times 10^{-3} \Omega \cdot \mathrm{cm}^{2}$ (Fig. 5). This is much higher than that of the ohmic contacts to $n-\mathrm{GaN}$; the $\rho_{\mathrm{s}}$ value estimated from the cutoff in the $R\left(1 / \pi r^{2}\right)$ curve is $\sim 10^{-2} \Omega \cdot \mathrm{cm}$. This value is in agreement with the data of other authors who studied ohmic contacts formed in the course of thermal annealing (at $T=700{ }^{\circ} \mathrm{C}$ ) of a gilded nickel film (Au-Ni) deposited onto the surface of $p-\mathrm{GaN}$ with $p \approx$ 


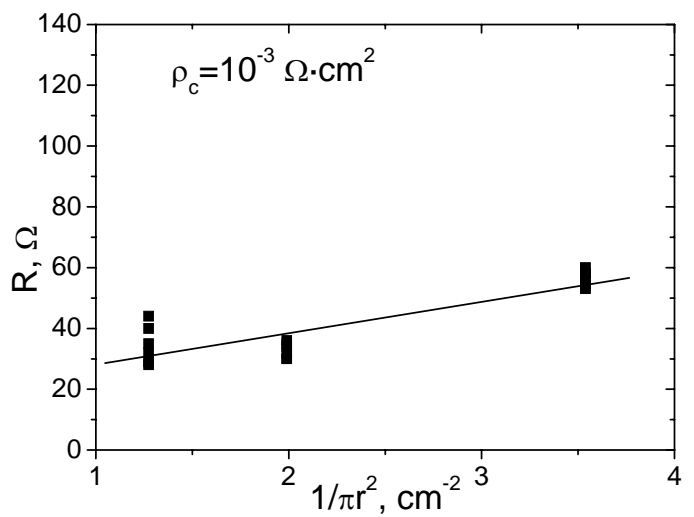

Fig. 5. The total resistance of $\mathrm{Au}-\mathrm{TiB}_{x}-\mathrm{Ni}-p-\mathrm{GaN}$ contacts as function of $\frac{1}{\pi r^{2}}$.

$10^{17} \mathrm{~cm}^{-3}$ [36]. In that case, the contact was formed by the $\mathrm{Ga}_{4} \mathrm{Ni}_{3}, \mathrm{Ga}_{3} \mathrm{Ni}_{2}, \mathrm{GaAu}$ and $\mathrm{GaAu}_{2}$ intermetallic phases that reduce the barrier at the interface between the above phases and $p-\mathrm{GaN}$. Production of $\mathrm{Ga}$ vacancies in the near-contact region that serve as acceptors [7] also favors reduction of $\rho_{\mathrm{c}}$ to $p$-GaN.

When comparing our data on $\rho_{\mathrm{c}}$ value with those of other authors $[6,7]$, one may assume that in our case, with $\mathrm{TiB}_{x}$ diffusion barrier, the contact-forming layer (after RTA at $T=700{ }^{\circ} \mathrm{C}$ ) is formed by the $\mathrm{GaNi}_{3}$ and $\mathrm{Ga}_{3} \mathrm{Ni}_{2}$ intermetallic phases, since the $\mathrm{TiB}_{x}$ layer prevents from penetration of $\mathrm{Au}$ atoms to the interface between $\mathrm{Ni}$ and $\mathrm{GaP}$. However, this should be confirmed with x-ray diffraction studies. In this case, one should not exclude also additional (positive) influence of $\mathrm{Ga}$ vacancies in the $p$-GaN near-contact region on decrease of $\rho_{\mathrm{c}}$. The repeated RTA $\left(700{ }^{\circ} \mathrm{C}, 60 \mathrm{~s}\right)$ did not change $\rho_{\mathrm{c}}$ value for the $\mathrm{Au}-\mathrm{TiB}_{x}-\mathrm{Ni}-p-\mathrm{GaN}$ ohmic contact. This fact indicates completeness of metallurgical reactions in the near-contact region and at the metal-GaN interface in the course of the first RTA.

The fact that $\rho_{\mathrm{c}}$ values are higher than those in the ohmic contact to $n$-GaN is determined by the features of doping of $p-\mathrm{GaN}$, e.g., owing to impurities passivation by hydrogen atoms in the course of MOCVD-growth and doping of $\mathrm{GaN}$ with uncontrolled donor impurities [37]. The complication results also from absence of metals with work function over $7.5 \mathrm{eV}$. Therefore, to make low-barrier ohmic contacts to $p$-GaN, one should either use contact-forming compounds with high work function values or form a heavily doped narrow-gap near-surface layer in $\mathrm{GaN}[3-5,30]$.

\section{Conclusion}

A comparison between the methods of measurement of contact resistivity of ohmic contacts to $n(p)-\mathrm{GaN}$ showed that TLM with circular contact geometry is optimal. Using the developed plant for measurement of ohmic contact parameters, we applied this method for study of electrophysical properties of ohmic contacts to $n$ - and $p$ -
$\mathrm{GaN}$. The contacts were multilayer $\mathrm{Au}-\mathrm{TiB}_{x}-\mathrm{Al}-\mathrm{Ti}-n$ GaN structures (that remained thermally stable after RTA at temperatures up to $900{ }^{\circ} \mathrm{C}$ [29]) and $\mathrm{Au}-\mathrm{TiB}_{x}-\mathrm{Ni}-p$ $\mathrm{GaN}$ structures (that remained thermally stable after RTA at temperatures up to $\left.700{ }^{\circ} \mathrm{C}\right)$. The $I-V$ curves of the $\mathrm{Ti}-\mathrm{Al}-\mathrm{TiB}_{x}-\mathrm{Au}$ contacts to the $n^{+}-n-n^{+}-\mathrm{GaN}$ structure were linear in the $90-380 \mathrm{~K}$ temperature range; the contact resistivity $\rho_{\mathrm{c}}$ at room temperature was $(6.69 \pm 1.67) \times 10^{-5} \Omega \cdot \mathrm{cm}^{2}$. For the $\mathrm{Au}-\mathrm{TiB}_{x}-\mathrm{Ni}-p-\mathrm{GaN}$ contact structure, $\rho_{\mathrm{c}}=(1 \pm 0.15) \times 10^{-3} \Omega \cdot \mathrm{cm}^{2}$, and the contact $I-V$ curves were.

Thus, the experimental results obtained by us indicate high thermal stability of ohmic contacts, with titanium boride as diffusion barrier, to $n$ - and $p$-GaN layers.

\section{Acknowledgements}

This work was supported by the Project No 31/4.2.3.1/33 of the Governmental task scientific and technical program "Development and implementation of energy-saving light sources and illumination systems based on them" (Regulation of the Cabinet of Ministers of Ukraine No 632 from July 9, 2008). The development of varactor diodes was carried out under the INCO-COPERNICUS Program (Project No 977131 “MEMSWAVE”).

\section{References}

1. F.E. Shubert, Light-Emitting Diodes, Cambridge University Press (2006).

2. Yu. Davidenko, High-efficiency modern LEDs // Sovremennaya Elektronika no 8, p. 36-43 (2004) (in Russian).

3. H. Morkoç, Handbook of Nitride Semiconductors and Devices, Willey-VCH (2008).

4. V.N. Danilin, Yu.P. Dokuchaev, T.A. Zhukova, M.A. Komarov, High-Power High-Temperature Capable and Radiation-Resistant Microwave NewGeneration Devices with AlGaN/GaN Wide-Gap Heterojunction Structures. Reviews of Electronic Equipment, GUP NPP "Pulsar", Moscow (2001) (in Russian).

5. Yu.G. Shretter, Yu.T. Rebane, V.A. Zykov, V.G. Sidorov, Wide-Gap Semiconductors, Nauka, Sankt-Peterburg (2001) (in Russian).

6. T.V. Blank, Yu.A. Gol'dberg, Semiconductor photoconverters for ultraviolet spectral region. A review // Fiz. Tekh. Poluprov. 37(9), p. 1025-1055 (2003) (in Russian).

7. T.V. Blank, Yu.A. Gol'dberg, The mechanism of current transport in ohmic metal-semiconductor contacts. A review // Fiz. Tekh. Poluprov. 41(11), p. 1281-1308 (2007) (in Russian).

8. N. Mochida, T. Honda, T. Shirasawa, A. Inoue, T. Sakaguchi, F. Koyama, K. Iga // J. Cryst. Growth 189-190, p. 716(1998). 
9. M.A. Nicolet, Diffusion barriers in thin films // Thin Solid Films 52(3), p. 415-443 (1978).

10. O.A. Ageev, A.E. Belyaev, N.S. Boltovets, R.V. Konakova, V.V. Milenin, V.A. Pilipenko, Interstitial Phases in Technology for Semiconductor Devices and VLSI, NTK "Institute of Single Crystals", Kharkov (2008) (in Russian).

11. V.N. Sheremet, The making features and electrophysical properties of ohmic contacts to gallium nitride (a review) // Optoelektronika i Poluprovodnikovaya Tekhnika 44, p. 41-59 (2010) (in Russian).

12. Chung-Yu Ting, Charles Y. Chen, A study of the contacts of a diffused resistor // Solid St. Electr. 14(6), p. 433-438 (1971).

13. V.N. Sheremet, Metrological aspects of measurement of ohmic contacts resistance // Izvestiya Vuzov. Radioelektronika 53(3), p. 3-12 (2010) (in Russian).

14. R.H. Cox, H. Strack, Ohmic contacts for GaAs devices // Solid St. Electr. 10(12), p. 1213-1218 (1967).

15. R.D. Brooks, H.G. Mattes, Spreading resistance between constant potential surfaces // Bell Sys. Tech. J. 50(3), p. 775-784 (1971).

16. S.S. Cohen, Contact resistance and methods for its determination // Thin Solid Films 104(3-4), p. 361379 (1983).

17. E.B. Kaganovich, S.V. Svechnikov, The methods of measurement of contact resistance of semiconductor planar structures (a review) // Optoelektronika i Poluprovodnikovaya Tekhnika 21, p. 1-11 (1991) (in Russian).

18. L.G. Russel, J.H. Michael, Y.R. Gary, The effect of lateral current spreading on the specific contact resistivity in D-Resistor Kelvin devices // IEEE Trans. Electr. Dev. 34(3), p. 537-543 (1987).

19. N. Stavitski, M.J.H. van Dal, J.H. Klootwijk, R.A.M. Wolters, A.Y. Kovalgin, J. Schmitz, CrossBridge Kelvin Resistor (CBKR) structures for silicide-semiconductor junctions characterization, in Proc. $9^{\text {th }}$ Annual Workshop on Semiconductor Advances for Future Electronics and Sensors, 2324 Nov 2006, Veldhoven, The Netherlands, p. 436438 (2006).

20. H.H. Berger, Contact resistance and contact resistivity // J. Electrochem. Soc. 119(4), p. 507514 (1972).

21. H.H. Berger, Models for contacts to planar devices // Solid St. Electr. 15(2), p. 145-158 (1972).

22. H. Murrmann, D. Wiedmann, Current crowding on metal contacts to planar devices // IEEE Trans. Electr. Dev. 16(12), p. 1022-1024 (1969).

23. H. Murrmann, D. Wiedmann, Messung des Übergangswiderstandes zwischen Metall und Diffusionsschicht in Si-Planarelementen // Solid St. Electr. 12(11), p. 879-886 (1969).

24. G.K. Reeves, H.B. Harrison, Obtaining the specific contact resistance from transmission line model measurement // IEEE Electron Device Lett. 3(5), p. 111-113 (1982).
25. A.N. Andreev, M.G. Rastegaeva, V.P. Rastegaev, S.A. Reshanov, To the problem of accounting for current spreading in a semiconductor when determining the transient resistance of ohmic contacts // Fiz. Tekh. Poluprov. 32(7), p. 832-838 (1998) (in Russian).

26. G.K. Reeves, Specific contact resistance using a circular transmission line model // Solid St. Electr. 23(5), p. 487-490 (1980).

27. D. Sawdai, Enhanced transmission line model structures for accurate resistance evaluation of small-size contacts and for more reliable fabrication // IEEE Trans. Electron. Dev. 46(7), p. 1302-1311 (1999).

28. M. Lijadi, F. Pardo, N. Bardou, J. Pelouard, Floating contact transmission line modelling: An improved method for ohmic contact resistance measurement // Solid St. Electr. 49(10) p. $1655-$ 1661 (2005).

29. A.E. Belyaev, N.S. Boltovets, V.N. Ivanov, L.M. Kapitanchuk, V.P. Kladko, R.V. Konakova, Ya.Ya. Kudryk, A.V. Kuchuk, O.S. Lytvyn, V.V. Milenin, V.N. Sheremet, Yu.N. Sveshnikov, Development of high-stable contact systems to gallium nitride microwave diodes // SQO 10(4), p. 1-8 (2007).

30. S. Noor Mohammad, Contact mechanisms and design principles for alloyed ohmic contacts to $n$ GaN // J. Appl. Phys. 95(12), p. 7940-7953 (2004).

31. M. Pidun, P. Karduck, J. Mayer, K. Heime, B. Shineller, T. Walther, Auger depth profile analysis and EFTEM analysis of annealed Ti/Alcontacts on Si-doped GaN // Appl. Surf. Sci. 179(14), p. 213-221 (2001).

32. S. Ruvimov, Z. Liliental-Weber, J. Washburn, D. Qiao, S.S. Lau, Paul K. Chu, Microstructure of Ti/Al ohmic contacts for $n-\mathrm{AlGaN} / /$ Appl. Phys. Lett. 73(18), p. 2582-2584 (1998).

33. W. Gotz, N.M. Johnson, C. Chen, H. Liu, C. Kuo, W. Imler, Activation energies of Si donors in GaN // Appl. Phys. Lett. 68(22), p. 3144-3146 (1996).

34. A.E. Belyaev, N.S. Boltovets, V.N. Ivanov, V.P. Klad'ko, R.V. Konakova, Ya.Ya. Kudryk, A.V. Kuchuk, V.V. Milenin, Yu.N. Sveshnikov, V.N. Sheremet, On the tunnel mechanism of current flow in $\mathrm{Au}-\mathrm{TiB}_{x}-n-\mathrm{GaN}-i-\mathrm{Al}_{2} \mathrm{O}_{3}$ Schottky barrier diodes // SQO 10(3), p. 1-5 (2007).

35. V.V. Evstropov, Yu.V. Zhilyaev, M. Dzhumaeva, N. Nazarov, Tunnel-excess current in III-V nondegenerate barrier $p$ - $n$ and $m-s$ structures on $\mathrm{Si} / /$ Fiz. Tekh. Poluprov. 31(2), p .152-158 (1997) (in Russian).

36. J.K. Shen, Y.K. Su, G.C. Chi, W.C. Chen, C.Y. Chen, C.N. Huang, J.M. Hong, Y.C. Yu, C.W. Wang, E.K. Lin, The effect of thermal annealing on thermal annealing on the $\mathrm{Au} / \mathrm{Ni}$ contact of $p-\mathrm{GaN} / / J$. Appl. Phys. 83(6), p. 3172-3175 (1998).

37. S.J. Pearton, F. Ren, A.P. Zhang, K.P. Lee, Fabrication and performance of $\mathrm{GaN}$ electronic devices // Mat. Sci. Eng. R 30(3-6), p. 55-212 (2000).

(C) 2010, V. Lashkaryov Institute of Semiconductor Physics, National Academy of Sciences of Ukraine 